\title{
Clube Guarani (1920-2006): tempos de luta contra o preconceito em Arroio Grande
}

Beatriz Floôr Quadrado ${ }^{1}$

Resumo: Este é um estudo sobre a história do Clube Guarani, localizado na cidade de Arroio Grande, fundado em 1920, devido ao preconceito racial que acabava proibindo a participação do negro em certos espaços sociais. A pesquisa faz um apanhado geral desta história, destacando o significado deste patrimônio cultural através das memórias da comunidade negra do município. Faz-se necessário, para um melhor entendimento, também uma análise da realidade da população afrodescendente no início da república, o preconceito por estereótipos excludentes do meio social. O método utilizado foi o da História Oral, vinculado aos estudos teóricos sobre memória e patrimônio.

Palavras- chaves: Clube Guarani; Discriminação; História Oral; Memória; Patrimônio.

Não faz muito tempo que a presença e a resistência negra têm sido estudadas e consideradas na historiografia, especificamente a gaúcha. O que não é difícil de compreender, afinal a presença negra na região ainda se faz renegada, mesmo que

${ }^{1}$ Acadêmica do curso de Licenciatura Plena em História da UFPel - $9^{\circ}$ semestre. Orientadora: Lorena Almeida Gill 


\section{Cadernos de Clio, Curitiba, n. ${ }^{\circ}$ 3, 2012}

o estado tenha uma quantidade relevante de afrodescendentes, cuja cultura e religião se fazem bastantes presentes.

O sistema mercantilista no século XV baseava-se na busca de poder através da expansão comercial, com entrepostos na Ásia e na África; e colonial, com destaque às Américas. E é nesta busca de maior dominação que se intensifica a expansão ultramarina, e há, com isso, o crescimento de colônias européias, bases do sistema. No Brasil, colônia de Portugal, o modo de produção adotado foi o escravista e a agricultura. Os escravos eram explorados com trabalhos num ritmo intenso e ainda viviam sob maus tratos e castigos. Estes eram utilizados apenas para o serviço que exigisse esforço e que não necessitasse de uma maior qualificação, sendo tais atitudes justificadas pelas ideias racistas dos colonizadores, através das quais os africanos eram classificados como inferiores e incapazes de realizar processos mais elaborados. Ideais estes também pregados pela Igreja e pelo Estado para a escravização. Ao contrário do que se tinha na historiografia de pouco tempo atrás, a mão-de-obra negra e escrava foi utilizada em grande número no Rio Grande do Sul, em especial nas charqueadas.

A resistência por parte dos escravos foi marcante dentro deste sistema e se deu de diferentes maneiras, por meio de fugas, quilombos, insurreições, carta de alforrias e negociações sendo intensificadas no período do Império. Nos anos 80 do século XIX houve por todo país movimentos abolicionistas, com destaque para 
o Ceará com José do Patrocínio e seu sistema de fugas; Rio de Janeiro; São Paulo; Amazonas; e também no Rio Grande do Sul.

Antes da abolição total da escravatura tiveram diversas leis, como o Projeto Dantas que proibia o tráfico de escravos entre as províncias e libertava os de idade superior a 60 anos, após trabalharem mais cinco anos. Em 1885 teve o Projeto Saraiva, o qual aumentou para mais três anos de serviço para a libertação dos idosos. Em seguida teve-se a "Abolição do Açoite", mas os movimentos continuaram cada vez mais intensos contra o regime escravista. Então, em 13 de maio de 1888, a Princesa Isabel assinou a Lei Áurea, para o fim da escravidão.

Segundo Jacob Gorender (1991), se analisarmos a realidade atual dos negros brasileiros, não houve abolição, ou seja, sofrem com a pobreza e discriminação. $\mathrm{O}$ que podemos afirmar é que não foi abolida a condição difícil e desigual, refletida na realidade vivida pelo povo negro. E para esclarecer, obviamente não houve o fim total da escravidão só com a assinatura da nova lei, ou seja, continuaram resquícios de escravismo no novo modo econômico, o capitalista.

Após a abolição da escravatura em 1888, a realidade vivida pela população negra continuou difícil, sendo marcada por estigmas ligados a vagabundagem, prostituição e vícios. A luta pela liberdade de negros ainda se fez presente de diversas formas, as mais representativas foram as associações de recreação e de esportes, 


\section{Cadernos de Clio, Curitiba, n. ${ }^{\circ}$ 3, 2012}

muito em vista no Rio Grande do Sul como, por exemplo, em Caxias, Pelotas, Arroio Grande e outros lugares. Segundo Beatriz Loner e Lorena Gill:

Trazido como escravo para esta região, o grupo negro tendeu, para o final do período imperial, a congregarse em entidades mutualistas, profissionais ou étnicas, que ainda não buscavam a construção de uma identidade racial, mas sim auxiliar na inclusão social e amparar seus sócios. Com a República, suas entidades evoluíram para a formação de uma rede associativa praticamente completa, surgindo propostas identitárias entre este grupo, embora sofresse com a influência desagregadora de ideologias, como a do branqueamento, com forte apelo na sociedade brasileira (2009, p:146).

Devido às teorias como a do branqueamento, em que relações interétnicas eram valorizadas para extinguir a "raça inferior", para isso houve uma intensificação da imigração. E é neste momento que a exclusão e o preconceito se intensificam, assim como a necessidade de identificação como grupo na sociedade. Um exemplo expressivo são os clubes sociais, conhecidos como Clubes Negros, em todo Brasil, inclusive no Rio Grande do Sul.

\section{Clube Guarani - Da discriminação às festas}


As terras em que hoje está situada a cidade de Arroio Grande foram um local de disputas entre Portugal e Espanha, onde no século XVIII, em busca de novos territórios foram tomadas por um militar do exército português, Rafael Pinto Bandeira. Este concedeu terras ao tenente Vasco Pinto Bandeira, nestas localizada a freguesia Nossa Senhora da Graça, com origem em 1812, através de terras doadas por Manuel de Souza Gusmão, avô do Barão de Mauá, para sua esposa. A cidade, que é emancipada de Jaguarão, apenas em 1872, teve como base de sustentabilidade as charqueadas, baseada na pecuária e na escravidão. Os escravos negros eram utilizados para trabalhos domésticos nas fazendas e olarias, com isso, nesta localidade há uma forte manifestação da cultura e religião africana. Em 1858, Arroio Grande tinha 3.929 habitantes, sendo que 1.833 eram escravos ${ }^{2}$. Percebe- se aí um número significativo da presença negra na região.

Como no restante do Brasil, estes passaram por períodos difíceis no início da república, isto se dava pela realidade vivida quando escravos, em que eram associados a estigmas ligados a vagabundagem, prostituição e vícios. Com isso, percebe-se uma exclusão destes do restante da sociedade, ratificada por teorias racialistas no século XIX para justificar e reforçar tal distinção. Segundo Gomes:

2 Fundação de Economia e Estatística De Província de São Pedro a Estado do Rio Grande do Sul-Censos do RS 1303-1950. Porto Alegre, 1981. 
Cadernos de Clio, Curitiba, n. ${ }^{\circ}$ 3, 2012

[...] no caso específico da população negra, não se pode esquecer que os estereótipos atribuídos a sua etnia são reflexos de uma construção social do que é "ser negro", baseada muitas vezes, em teorias que pregavam sua inferioridade biológica, cultural e moral (2008, pg. 48).

Dentre estas teorias pode-se destacar a de Nina Rodrigues, no século XIX, que faz uma diferenciação, em termos de superioridade, de brancos sobre afrodescendentes. Tem-se também João Batista Lacerda, no mesmo século, com a teoria de branqueamento, em que se via a possibilidade, através da mestiçagem, de hegemonizar a raça branca.

É sob esta realidade e ideologias que surge o Clube Guarani em 1920, como resposta à discriminação. Este surgiu através de um grupo de amigos: João Lúcio, Alvião Lúcio, Idílio Freitas, Carlos Ferreira, Evaristo Cardoso e, como presidente, João Medeiro. Para os frequentadores, o Clube era uma grande família, e nota-se que realmente algumas famílias negras se destacam na direção, organização e participação no clube, sendo também que muitas uniões foram feitas entre elas.

O nome dado à associação, Clube Guarani, segundo frequentadores mais recentes, foi para desviar o foco da cor da pele sobre o clube, ou seja, pode se pensar que a associação foi criada como um meio social, para festas e reuniões, sem diferenciação 
Cadernos de Clio, Curitiba, n. ${ }^{\circ}$ 3, 2012

étnica ou racial, por isso um nome sem classificação real do verdadeiro grupo discriminado, o qual necessitou de um espaço para conviver em sociedade.

Tal agremiação tinha um caráter social, pois em outras duas associações da cidade, atualmente Clube Caixeiral e Clube do Comércio, e também no CTG, não era permitida a entrada de negros. O primeiro clube citado era bem mais rígido na questão da proibição da entrada de negros na sede do que a segunda instituição. Conforme o Estatuto do Clube Guarani, renovado no ano de 1957, este tinha por objetivo: "Proporcionar aos seus associados festas de qualquer natureza, especialmente bailes, não sendo estes menos de seis, por ano; obras de arte, quermesses, etc." ${ }^{3}$. Então se percebe a necessidade de um lugar para fazerem suas próprias festas. No início havia, além da direção, os "presidentes de honra", entre estes alguns homens brancos, os quais colaboravam financeiramente para manter o clube, ou seja, para manter a distinção, por exemplo: o jornalista Aimone Soares Carriconde; Issa Costa e Osmar Machado.

A presidência do clube era renovada por convite feito pela antiga diretoria, mas em 1956 são realizadas as primeiras eleições em que a gestão era por um ano. A partir de 1978 passa a ser de dois anos. Até 2005 só tiveram homens no comando da associação.

\footnotetext{
${ }^{3}$ Anexo do projeto "Reconstruindo a História do clube Guarani” feito especialmente por Gizelaine Diogo da Conceição, atual vice- presidente do Clube Guarani, no ano de 1999.
} 
As mulheres participavam do chamado "Clube da Casa da Amizade", em que organizavam alguns encontros, festas e chás. Esta era uma espécie de segunda diretoria, e de grande relevância, pois enquanto os homens cuidavam da parte financeira $\mathrm{e}$ administrativa da associação, elas participavam da construção da "alma" do clube, ou seja, as festas, o social. Nas festas eram permitidas apenas mulheres maiores de 18 anos, menores deveriam ser acompanhados pelos responsáveis.

Havia também uma atenção para manter sempre o bom comportamento e a boa aparência, com a finalidade de afastar os estereótipos de inferioridade atribuídos a cor. Quando perguntei a uma antiga frequentadora sobre as exigências sobre a aparência e vestimentas, ela claramente colocou a relevância e a evidência do "se vestir bem":

Tu não vai vir com uma sainha, mas em outros lugares assim ó, têm lugares que tu entra e te olham dos pés à cabeça, parece que tu ta praticamente sem roupa né? E assim, olha e já vê que a roupa é mais usada, entendesse? Ah, mas o que que tem eu vir de rasteirinha, se eu não tenho, tô bem arrumada, não to rasgada, não to suja $?^{4}$

\footnotetext{
${ }^{4}$ Carla Figueeiredo, 26 de Fevereiro de 2011, entrevistadas por Beatriz Floôr Quadrado; Marília Floôr Kosby.
} 
Além disso, era possível a entrada de brancos. Segundo frequentadores, não havia distinção de raça e nem distinção financeira, ou seja, o clube era aberto a toda comunidade arroiograndense. Segundo as entrevistadas:

Acho que as pessoas se sentiam bem à vontade. [?] chegavam aqui e podiam ser elas, não precisava representar uma coisa que ela não era, entende? Podiam ser elas mesmos. ${ }^{5}$

Vinha tanto pobre quanto o que tinha a situação financeira melhor. ${ }^{6}$

Não, e se sentiam meio[?], as vezes tu ia... eu me lembro assim ó, de ir nos outros clubes e tu ficava em grupo, certo? Aqui não, aqui todo mundo se misturava, não interessa se tu era vermelho, verde, amarelo né, preto. ${ }^{7}$

Percebe-se, pelas entrevistas, que no início o propósito era de diferenciação, pois neste período era restrita a entrada de brancos no clube, principalmente para aqueles que de alguma forma ajudavam financeiramente. Conforme Giacomini (2006), sobre os clubes negros: "Estar entre os seus era, também, necessariamente, diferenciar-se de outros" (p.34). Era uma forma de se colocarem perante a sociedade como grupo, além de resistir ao preconceito

\footnotetext{
${ }^{5}$ Carla Figueeiredo, 26 de Fevereiro de 2011, entrevistadas por Beatriz Floôr Quadrado; Marília Floôr Kosby.

${ }^{6}$ Maria Geni Lemos (Ziza), 26 de Fevereiro de 2011, entrevistadas por Beatriz Floôr Quadrado; Marília Floôr Kosby.

${ }^{7}$ Carla Figueiredo, 26 de Fevereiro de 2011, entrevistadas por Beatriz Floôr Quadrado; Marília Floôr Kosby.
} 
racial, em que percebiam a diferença imposta, uma forma de valorizar esta diferença a seu favor para conseguirem o seu espaço.

No Clube Guarani existiam diversas festas, como o Baile de Primavera; Bailes de Carnaval; o Baile das Rosas, em que se comemorava o início da primavera; Bailes de posse, realizados nas renovações da direção do clube; Baile de Debutantes; Festa Kizomba (em Yorubá, é festa de integração), na qual havia bingos e atos religiosos e também as "Quermesses", que contribuíam para a arrecadação de dinheiro à associação e havia blocos de carnavais, como exemplo, o "Bloco Sempre Reinando", de 1938. Os concursos de beleza também se faziam presentes nesta agremiação, como forma de valorização da beleza negra, entre os quais o "concurso Broto" e "Miss Mulata". Segundo um ex-presidente e frequentador, estes concursos tinham o objetivo de: "Valorizar e mostrar que negro é gente." 8

O grande organizador do concurso Miss Mulata foi Antônio Carlos da Conceição, conhecido como Dé, que, inclusive, antes de ser presidente do Clube Guarani, nos anos 90, foi decorador de várias festas no clube do Comércio e Clube Caixeiral. Segundo Dé, ele não percebe mais tanto preconceito, mas confessa ter sofrido muito quando professor de história na rede pública na

\footnotetext{
8 Antônio Carlos da Conceição, de Arroio Grande, 5 de Agosto de 2011, entrevistado pela oficina de patrimônio do ponto de cultura Axé Raízes. / Entrevista feita através da oficina de Patrimônio em que era monitora.
} 
cidade, até mesmo por ter sido o primeiro professor negro nesta escola.

Quando perguntado sobre as festas, ele responde que eram um espetáculo e fala mais:

[...] não, mas os bailes [...] sabes que, inclusive os bailes de debutante eram um luxo né? Não havia diferença nenhuma do comércio. Inclusive eu ia a Pelotas trazia as flores de ônibus e quem decorava, eu decorava o clube pro baile dos debutantes. Era, aquela escadaria, era um luxo aquilo dali com flores. Que eu fazia com prazer, porque o que a gente faz com prazer as coisas saem tudo certinho. $\mathrm{O}$ baile das debutantes era um luxo era,o Guarani, as pessoas, Que antigamente as pessoas corriam pra ver a entrada das pessoas no baile de debutantes no comercio, as pessoas faziam a mesma coisa lá no Guarani. As pessoas brancas pra ver a entrada das meninas que iam debutar. Era um luxo o Guarani. Era uma sociedade que naquela época era também uma sociedade fechada, assim como o Comércio e o Caixeral eram. Principalmente o comercio, o guarani também não era qualquer pessoa que entrava ali. ${ }^{9}$

O Miss Mulata foi organizado por ele durante 30 anos, tendo sido o último realizado em 1999. Para Dé, o concurso tinha este nome, pois acredita que não se tem mais um "negro puro", mas sim uma mistura, por isso se referir a mulata e não a negra, além de

9 Antônio Carlos da Conceição, de Arroio Grande, 5 de Agosto de 2011, entrevistado pela oficina de patrimônio do ponto de cultura Axé Raízes. I Entrevista feita através da oficina de Patrimônio em que era monitora. 


\section{Cadernos de Clio, Curitiba, n. ${ }^{\circ}$ 3, 2012}

já ter existido um concurso no Estado de "Miss Negra". O concurso movimentava o município e era muito respeitado em toda a região, com participantes e visitantes de muitas outras cidades.

Todos os entrevistados colocavam a diferença do Guarani sobre os outros clubes, como melhor festa até mesmo para brancos, como a mais alegre e animada. Para Gizelaine: "Lá tinha diferença de classe, no clube deles. E aqui não, aqui todo mundo era igual. Independente da raça, mas todo mundo era igual. Tu tinha dinheiro, tu não tinha dinheiro[...]"10

Percebe-se que esta diferença colocada pelas entrevistadas, é uma forma de reafirmação de grupo, pois se identificam em seu clube e se diferenciam das outras entidades, colocado, no caso, como mais animado e sem preconceitos. Foi visível em todos frequentadores procurados a necessidade desta afirmação, e definição enquanto grupo. Também, segundo Giacomini,"estar entre os seus era, também, necessariamente, diferenciar-se de outros. Assumir e ostentar as marcas de distinção constitui, assim, um elemento central da prática, mas também do projeto do grupo" (2006, p: 34).

Arroio Grande em sua história foi marcada por episódios lamentáveis de discriminação como, por exemplo, no caso de um estudante, em 1977, barrado em um baile de sua escola realizado no

${ }^{10}$ Gizelaine Diogo Conceição (Giza), 26 de Fevereiro de 2011, entrevistadas por Beatriz Floôr Quadrado; Marília Floôr Kosby. 
CTG Tropeiros da Querência. Este caso repercutiu na imprensa regional, destacando as diferenças de tratamento em outros âmbitos sociais, como a discriminação de Clubes Sociais proibindo a entrada de negros. Para Antônio Carlos da Conceição: "Era muito difícil ser negro em Arroio Grande". ${ }^{11}$

Ainda segundo Dé, houve na cidade um concurso, chamado "Miss Tv", em que a representante de Arroio Grande foi uma mulher negra, mas a cidade não levou esta para continuar com as eliminatórias em outras cidades. Não seria um preconceito não dar continuidade no concurso?!

Em uma reunião com os associados há uma manifestação de uma antiga sócia, que coloca que um negro não se sente bem em clube de brancos e que se estes têm uma elite, os negros também têm dentro de seu próprio clube. Diz para que os presentes na reunião não deixem suas filhas serem rainhas de clubes de brancos, pois serão diminuídas. E expressa a vontade de subir novamente as escadas do clube e, segundo ela: "pular junto da minha negrada".

Nos anos 60 o clube passou por uma reforma em sua sede, na presidência de Laureci Pires, em que foi construído um segundo piso para sua ampliação. Para isso obteve ajuda de sócios, ou seja, o prédio foi reconstruído pelos próprios frequentadores, a qual trouxe como consequência gastos para este, que para tentar suprir foram

\footnotetext{
${ }^{11}$ Carlos, de Arroio Grande, 5 de Agosto de 2011, entrevistado pela oficina de patrimônio do ponto de cultura Axé Raízes.
} 
realizadas festas feitas no chamado "salão Metálico", alugado para tal fim. A partir do ano de 1997 começa a viver uma grande crise devido a dívidas, como as do ECAD (Escritório Central de Arrecadação e Distribuição). O clube seguia com algumas festas na sexta- feira, as chamadas Boates "Nova Geração".

Em 2001 o clube fecha suas portas devido às dívidas e à estrutura precária do prédio. Este é levado a leilão, mas não houve compradores. O Clube fica abandonado até 2004, quando se têm na presidência duas mulheres Gizelaine Diogo Conceição e Maria Geni Lemos. Com elas o clube consegue resgatar em média 150 sócios, pagar o ECAD e outras dividas que vinha acumulando, como CEEE e Corsan. Em novembro de 2005 é inaugurado o novo salão de festas, chamado José Inácio Balhego.

\section{A comunidade fecha o Guarani}

A associação, que até então vinha se recuperando, é fechada legalmente em 2006. Segundo frequentadores, de maneira autoritária, agressiva e sem negociações, devido a reclamações relacionadas aos barulhos das festas e reuniões realizadas no Guarani, mobilizando vizinhos e até mesmo moradores de outros bairros distantes da localidade contra o clube. Nesse período a diretoria, pela primeira vez, era composta por duas mulheres antes tão exaltadas por salvarem a instituição, e então, diante de uma dificuldade são tratadas como responsáveis únicas pelo fechamento, 
ligando o fim do clube a administração feminina. Segundo as presidentes foi um período muito difícil:

Foi muito agressivo. E eu não quis...eu tava a frente, eu era a presidente, hoje eu sou a vice e a Ziza é a presidente. Eu era a presidente e eu não quis levar pro fato do racismo, entendesse? Eu tinha essa carta na manga. Não quis por causa que assim eu não iria resolver o meu problema, eu ia passar o meu problema pros outros. Até hoje eu permaneço com a cabeça bem tranqüila do que as pessoas pensam ou deixam de pensar no que aconteceu. Muita gente nos perguntava: "Bah vocês vão deixar o clube $[\ldots] .{ }^{12}$

Pelo fato de ser mulher né.

[?] "Ah vocês fecharam o clube" [?] "Vocês no mínimo roubavam"13

Foram feitos abaixo-assinados tanto para fechar a agremiação, quanto para mantê-la funcionando, mas este último, que continha mais assinaturas, segundo os frequentadores, não foi aceito pela promotora. As insatisfações dos vizinhos também se davam pelos barulhos dos carros que passavam na frente do clube e

\footnotetext{
${ }^{12}$ Diogo Conceição (Giza), 26 de Fevereiro de 2011, entrevistadas por Beatriz Floôr Quadrado; Marília Floôr Kosby.

${ }^{13}$ Maria Geni Lemos (Ziza) 26 de Fevereiro de 2011, entrevistadas por Beatriz Floôr Quadrado; Marília Floôr Kosby.
} 


\section{Cadernos de Clio, Curitiba, n. ${ }^{\circ}$ 3, 2012}

de pessoas sentadas nas beiras das calçadas, tudo passava a ser responsabilidade do Guarani. Segundo Gizelaine, nenhuma reclamação chegou até seu conhecimento, apenas com o processo, por meio do qual foi interditado um local de representação de um grupo social de quase 100 anos. Sendo que as demais agremiações não possuem qualquer planejamento em relação ao sistema de som. E ainda, o Clube do Comércio é localizado a uma quadra do Guarani. A única possibilidade de reativar o clube é colocando um sistema de isolamento acústico, o que era inviável em termos financeiros, ainda mais sem poder fazer festas e eventos, sob pena de multa.

Foi mais um período de lutas, mais especificamente, da presidente Gizelaine para que o clube continuasse em funcionamento. $\mathrm{O}$ clube teve um prazo de cinco meses para resolver a sua situação, mas sem dinheiro, a maneira encontrada por ela foi buscar ajuda da prefeitura municipal. Gizelaine foi até em uma sessão da Câmara de vereadores pedir socorro pelo Clube Guarani, mas pelo que se sabe não se teve resultados. E com isso o clube é fechado legalmente.

\section{Ponto de Cultura Axé Raízes}

Em 2010 houve a seleção para o projeto "Pontos de Cultura" da Universidade Federal do Rio Grande (FURG), junto ao Ministério da Cultura. A cidade concorreu com as seguintes 
propostas: "Axé Raízes do Clube Guarani e o Samba" e "Cultura e Arte da Escola de Samba Unidos do Promorar".

O Clube Guarani é o escolhido, e é inaugurado como "Ponto de Cultura Axé Raízes", em 2011, na própria sede, então reformada. Com o objetivo de resgatar culturas e a construção de cidadania, através de oficinas como as de dança, capoeira, patrimônio, artes, literatura entre outras. Antes de iniciar esta nova etapa do clube houve uma reunião para expor tal projeto aos antigos sócios. Mas foi visível e inegável o desejo de antigos frequentadores pela reabertura do clube. $\mathrm{O}$ mesmo desejo de ter o clube como um centro social foi destaque na inauguração do ponto de cultura, entre os presentes surgiu à seguinte frase de um antigo frequentador: "Tá e que horas que começa a festa?". ${ }^{4}$

O prédio caracteriza um patrimônio cultural, material e imaterial, pois é um símbolo de identidade, interação e expressões coletivas, sendo também um estímulo de memória em que se reconstroem histórias de resistência, ou seja, ponto de referência da raça negra. Por isso tantas histórias e lembranças se manifestaram naquele momento de retorno da entidade, agora com outro enfoque. Segundo Antônio Augusto Arantes:

\footnotetext{
${ }^{14}$ Diário de Campo da autora, no dia 19 de Março de 2011 na sede do Ponto de Cultura Axé Raízes (Arroio Grande).
} 
Cadernos de Clio, Curitiba, n. ${ }^{\circ}$ 3, 2012

[...] são as edificações e as paisagens naturais. São também as artes e os ofícios, as formas de expressão e os modos de fazer. São as festas e os lugares a que a memória e a vida social atribuem sentido diferenciado: são as consideradas mais belas, as mais lembradas, as mais queridas. São fatos, atividades e objetos que mobilizam a gente mais próxima e que reaproximam os que estão longe, para que se reviva o sentimento de participar e de pertencer a um grupo, de possuir um lugar. Em suma, referências são objetos, práticas e lugares apropriados pela cultura na construção de sentidos de identidade, são o eu popularmente se chama de raiz de uma cultura (ARANTES apud FREIRE. 2005, p:13).

Estavam presentes na inauguração autoridades do município, como o prefeito, Jorge Cardoso; representantes da FURG; representantes da secretária de Cultura; o presidente da Câmara de vereadores, Itamar Botelho da Silva; entre outros. Além da presença das presidentes que foram mantidas, Gizelaine e Maria Geni. Neste momento de renovação e retorno do Clube para a comunidade, os presentes na mesa reforçaram e relembraram a história e a relevância do Guarani para a cidade de Arroio Grande, inclusive os políticos que já ocupavam seus cargos na prefeitura na época do fechamento da associação, para os quais foi pedida ajuda naquele período.

Ao falar, a presidente Maria Geni, emocionou-se ao se lembrar do clube e de todas as histórias vivenciadas nas 
dependências do Guarani. E disse: "o que passou, passou...", referindo-se, provavelmente, à interdição do local em 2006.

E a partir desta nova etapa, o Ponto de Cultura vem se destacando com seus projetos e realizações junto à comunidade.

\section{Conclusão}

O Clube Guarani se fez por quase cem anos um ponto de referência da comunidade negra. Segundo Giane Escobar, “[...] os negros conseguiram romper com a sociedade a fundar os seus espaços de sociabilidade, solidariedade e defesa de direitos." (2010, p.72) Por isso se faz necessário o trabalho do historiador de manter em evidência a ação negra diante da repressão que viveu durante muito tempo, e assim poder explicar, entender e procurar alternativas de mudança no conhecimento do passado.

Percebe-se a necessidade e importância para tal fim da história oral, um método que nos permite o conhecimento por meio de memórias pessoais, estas fundamentais para preservação de uma identidade. A memória é significada como “[...] expressões da realidade [...] um fenômeno coletivo e social, ou seja, como um fenômeno construído coletivamente e submetido a flutuações, transformações, mudanças constantes.” (Pollack, 1992, p.2) Esta está intimamente ligada à ideia de identidade e: 
Cadernos de Clio, Curitiba, n. ${ }^{\circ}$ 3, 2012

A construção da identidade é um fenômeno que se produz em referência aos outros, em referência aos critérios de aceitabilidade, de admissibilidade, de credibilidade, e que se faz por meio da negociação direta com outros. Vale dizer que memória e identidade podem perfeitamente ser negociadas, e não são fenômenos que devam ser compreendidos como essências de uma pessoa ou de um grupo (Pollack, 1992, p. 5).

Memórias estas em evidência, que ao serem trabalhadas e valorizadas contribuem para não "deixar cair no esquecimento", e assim facilitar a manipulação de informações para tomada de poder de ideias contrárias sobre fatos e ideais, criando falsas identidades. O Clube Guarani foi fechado e parece não ter recebido nenhum apoio para continuar funcionando, nem mesmo foi considerada sua importância histórica.

É relevante destacar que muitos acontecimentos não vividos pelos entrevistados foram relatados com detalhes e sentimentos. Fatos estes vividos por familiares, amigos, conhecidos, mas lembrados, chamado por Pollack de "acontecimentos vividos por tabela", ou seja, a pessoa pode não ter vivido tal momento, mas ela se sente pertencente, muitas vezes por ser um fato coletivo.

Concluindo, mesmo fechado o clube continua representando uma luta que se teve no passado e que ainda perdura, a luta contra o preconceito racial. Não se têm mais as festas, o carnaval, o Miss mulata, os bailes de Debutantes, as boates na 
sexta-feira, ainda tão desejado por antigos sócios e frequentadores do clube. Mas agora resiste, em sua antiga sede, porém com outro nome, agora "Axé Raízes", e outra finalidade, não de festa, mas de cultura, em especial a valorização da cultura afro. Como nos coloca uma ex- sócia do clube: "Cultura também é festa". Com isso, percebe-se a capacidade do patrimônio e de seu valor simbólico de despertar memórias, mesmo renovado ainda é lembrado como Clube Guarani.

\section{Referências:}

CONRAD, Robert. Os Últimos Anos de Escravatura no Brasil. Rio de Janeiro: Civilização Brasileira, 1975.

DELGADO, Lucília de Almeida Neves. História Oral: Memória, Tempos, Identidades. $2^{\circ} \mathrm{Ed}$, Belo Horizonte, Autêntica, 2010.

ESCOBAR, Giane Vargas. Clubes sociais negros: lugares de memória, resistência negra, patrimônio e potencial. Dissertação de Mestrado, Universidade Federal de Santa Maria. Programa de Pós-Graduação Profissionalizante em Patrimônio Cultural de 2010. FREIRE, Beatriz Muniz. O inventário e o Registro do Patrimônio Imaterial: Novos Instrumentos de preservação. Cadernos do LEPAARQ. Vol. II, n 3, Pelotas, RS, Editora da UFPel. Jan/Jul 2005. 
GIACOMINI, Sonia Maria. A Alma da Festa: família, etnicidade e projetos num clube sócia da Zona Norte do Rio de Janeiro. $\mathrm{O}$ Renascença Clube. Belo Horizonte: Editora UFMG; Rio de Janeiro, IUPERJ, 2006.

GOFF, Jacques Le. História e Memória. $5^{\circ}$ Ed, Campinas, Unicamp, 2003.

GOMES, Fabrício Romani. Sob a Proteção da Princesa e de São Benedito: identidade étnica, associativismo, e projetos num clube negro de Caxias do Sul (1934-1938). Dissertação de Mestrado, Universidade do Vale do Rio dos Sinos. Programa de Pós-Graduação de 2008.

GORENDER, Jacob. A Escravidão Reabilitada. São Paulo, Ática, 1991.

. O escravismo Colonial. São Paulo, Ática, 1978.

HALBAWACHS, Maurice. A Memória Coletiva. São Paulo: Centauro, 2004

KOSBY, Marília Floôr. Cultura e Patrimônio: Breves considerações sobre a presença negra na região de Arroio grande/RS. Revista Viva Cultura. , v.1, p.12 -*14* 2010.

LONER, Beatriz Ana, GILL, Lorena Almeida. Clubes Carnavalescos Negros na cidade de Pelotas. Estudos IberoAmericanos, Porto Alegre, v. 35, n. 1, p. 145-162, jan./jun. 2009.

MAESTRI, Mário. Pampa Negro- Quilombos no Rio Grande do Sul. In: REIS, João José; GOMES, Flávio dos Santos (org.). 
Liberdade por um Fio. São Paulo, Companhia das Letras, 1996, p. 291-331.

MEIHY, José Carlos Sebe Bom. História Oral: como fazer, como pensar. São Paulo, Contexto, 2007. p.9-59.

MOREIRA, Paulo Roberto Staudt. Etnicidade e Liberdade: as nações africanas e suas práticas de alforria. In: Ciências \& Letras. Porto Alegre: FAPA, nr. 44, jul./ dez.2008, p.167-186.

MOREIRA, Paulo Roberto Staudt. Justiçando o Cativeiro: a Cultura de Resistência Escrava. IN: BOEIRA, Nelson (Coord.), GOLIN, Tau (Coord.). História do Rio Grande do Sul- Império. Passo Fundo, Méritos, 2006.

NOVAIS, Fernando. O Brasil nos Quadros do antigo sistema colonial. IN: MOTA, Carlos G. (org). Brasil em Perspectiva. São Paulo, Difel, 1978, p.47-63.

POLLACK, Michael. Memória e Identidade Social. Estudos Históricos, Rio de Janeiro. vol.5. n.10, 1992, p.200-212.

PORTELLI, Alessandro. A Filosofia e os Fatos: narração, interpretação e significado nas memórias e nas fontes orais. Rio de Janeiro, Tempo, 1996. Vol.1, n², p.59-72.

PORTELLI, Alessandro. Tentando Aprender um pouquinho, algumas reflexões sobre a ética na história Oral. São Paulo: Projeto História, 1997. 
Cadernos de Clio, Curitiba, n. ${ }^{\circ}$ 3, 2012

REIS, Maria Clareth Gonçalves. Origens e significados do termo raças. Disponível em: <http://www.acordacultura.org.br/artigo-1205-2011>. Data de Acesso: 22/3/2012 THOMPSON, Paul. A voz do passado: história oral. Rio de Janeiro, Paz e Terra, 1992. 